\title{
PERTUMBUHAN BEBERAPA JENIS BIBIT TANAMAN MANGROVE SEBAGAI BIBIT SIAP TANAM DI BALAI KARHUTLA WILAYAH JAWA BALI NUSA TENGGARA
}

\section{GROWTH OF SEVERAL SPECIES OF MANGROVE SEEDLINGS AS SEEDS READY FOR PLANTING IN, KARHUTLA CENTRE OF JAVA, BALI, AND NUSA TENGGARA}

\author{
I Ketut Endra Primantara, A.A.Ketut Darmadi dan I Ketut Ginantra \\ Prodi Biologi, FMIPA, Universitas Udayana, Bukit Jimbaran - Bali \\ Email : Endra148@gmail.com
}

\section{INTISARI}

Hutan mangrove mempunyai peranan sangat penting dalam ekosistem daerah pesisir, misalnya menanggulangi abrasi laut, tempat sarang burung, membentuk keseimbangan ekologi, menangkap dan melokalisasi sedimen, mencegah keasaman tanah dan menghambat intrusi air laut. Keberhasilan reboisasi mangrove sangat ditentukan oleh keberhasilan dalam penyiapan semai mangrove. Bedeng pembibitan dibuat dari bambu untuk menampung 4 jenis semai mangrove yaitu Bruguiera gymnorrhiza, Rhizopora apiculata, Rhizopora mucronata dan Rhizopora stylosa dengan 6 ulangan dan masing-masing 3 individu tiap jenis. Variabel yang diukur adalah tinggi tanaman, jumlah daun dan diameter batang. Analisis statistik dengan program Costat \& Co. Hasil penelitian menunjukan ratarata pertumbuhan tinggi batang dari ke-4 semai mangrove yang diukur dari $6-13$ MST berturut-turut yaitu $1,5 \mathrm{~cm}, 1,4 \mathrm{~cm}, 0,8 \mathrm{~cm}$ dan $0,7 \mathrm{~cm}$. Rata rata jumlah daun dari ke-4 semai mangrove berturut-turut yaitu $0,6,1,2,0,6$, dan 0,6 helai dan rata-rata diameter batang ke-4 semai mangrove adalah $0,1 \mathrm{~cm}$. Tanaman semai mangrove jenis Rhizopora mucronata dan Bruguiera gymnorrhiza yang menghasilkan rata-rata pertumbuhan tinggi batang yang lebih tinggi dibandingkan lainnya, dan jenis Bruguiera gymnorrhiza yang menghasilkan rata-rata jumlah daun yang paling tinggi dibandingkan ketiga jenis lainnya.

Kata kunci ; semai, mangrove, pertumbuhan

\section{ABSTRACT}

Mangrove forests have important role in coastal ecosystems, for example to overcome marine abrasion, bird nesting sites, forming ecological balance, capturing and localizing sediments, preventing soil acidity and inhibiting sea water intrusion. The success of mangrove reforestation is largely determined by the success in preparing mangrove seedlings. Nursery beds made of bamboo to accommodate 4 species of mangrove seedlings, that are Bruguiera gymnorrhiza, Rhizopora apiculata, Rhizopora mucronata and Rhizopora stylosa with 6 replications and each of 3 individuals of each type. The variables measured were plant height, number of leaves and stem diameter. Statistical analysis with the Costat \& Co. program The results showed that the average growth of stem height from the 4 mangrove seedlings measured from $6-13$ MST was $1.5 \mathrm{~cm}, 1.4 \mathrm{~cm}, 0.8 \mathrm{~cm}$ and $0.7 \mathrm{~cm}$ respectively. The average number of leaves from the 4 mangrove seedlings were $0.6,1.2,0.6$, and 0.6 strands respectively and the average stem diameter of the 4 mangrove seedlings was $0.1 \mathrm{~cm}$. The mangrove seedlings of Rhizopora mucronata and Bruguiera gymnorrhiza species that produced higher growth rates of stem height than others, and Bruguiera gymnorrhiza which produced the highest average number of leaves compared to the other three types.

Keywords ; seedlings, mangroves, growth

\section{PENDAHULUAN}

Mangrove merupakan vegetasi peralihan antara darat dan laut yang sangat dipengaruhi oleh faktor-faktor lingkungan seperti, iklim tropik dan curah hujan yang tinggi, keadaan laut yang tenang serta adanya sumber lumpur. Tempat tumbuh hutan mangrove umumnya berupa lumpur atau lumpur berpasir, sehingga jenis pohon yang menyusun formasi hutan mangrove berbeda-beda antara tempat yang satu dengan tempat yang lainnya, tergantung dari jenis tanahnya, intensitas genangan air laut, kadar garam dan daya tahan terhadap ombak dan arus.

Hutan mangrove memiliki variasi yang khas untuk jenisjenis vegetasi dan daerah zonasinya, mangrove juga merupakan ekosistem yang memiliki produktifitas yang sangat tinggi. Tanaman mangrove dapat tumbuh pada garis pasang surut, pada pantai berkarang, pada karang mati, yang di atasnya ditimbuni selapis tipis pasir atau lumpur dan juga pantai yang berlumpur.

Menurut Soegianto (1986) Rhizophora mucronata tumbuh di pantai yang berlumpur yang pukulan ombaknya tidak terlalu kuat. Jenis Bruguiera gymnorrhiza yang juga termasuk familia Rhizophoraceae jika dibandingkan dengan Rhizophora mucronata lebih suka tumbuh di bagian yang kering. Perapat yang terdiri dari jenis Sonneratia alba dan Sonneratia casiolaris, kedua jenis tanaman itu mempunyai tempat tumbuh yang berbeda pula. Sonneratia alba lebih menyukai air laut dan
Sonneratia casiolaris lebih suka tumbuh di bagian tengah hutan mangrove yang berlumpur dengan air payau mendekati tawar.

Hutan mangrove mempunyai peranan penting dalam ekosistem di daerah pesisir, misalnya menanggulangi abrasi air laut, tempat tumbuh berbagai jenis tanaman mangrove, tempat sarang burung, membentuk keseimbangan ekologi, menangkap dan melokalisasi sedimen, mencegah keasaman tanah dan menghambat intrusi air laut (Suryadipura, 2004).

Keberhasilan suatu reboisasi atau penghijauan di daerah mangrove sangat diperlukan untuk konservasi hutan mangrove. Keberhasilan penghijauan mangrove ini sangat ditentukan oleh penyediaan bibit mangrove yang baik, untuk itulah maka penelitian ini dilakukan.

Berdasarkan penelitian ini untuk mengetahui pertumbuhan mana yang memiliki tinggi batang, jumlah daun dan diameter batang yang baik dari ke empat jenis semai mangrove seperti Bruguiera gymnorrhiza, Rhizopora apiculata, Rhizopora mucronata dan Rhizopora stylosa.

\section{MATERI DAN METODE}

Tempat dan waktu penelitian

Penelitian ini dilaksanakan di Balai Pengendalian Perubahan Iklim ( PPI ), Kebakaran Hutan dan Lahan ( KARHUTLA ) Wilayah Jawa Bali Nusa Tenggara yang terletak 
di Desa Pemogan, Kecamatan Denpasar Selatan, Kodya Denpasar, Provinsi Bali. Waktu penelitian dilaksanakan mulai bualan Juni sanpai Agustus 2018.

\section{Cara kerja}

Survei lapangan dilakukan untuk menentukan jenis bibit tanaman yang digunakan dan penentuan lokasi pembibitan. Bibit disiapkan dengan menggunakan 4 jenis bibit yang berbeda yaitu Rhizopora mucronata, Rhizopora stylosa, Rhizopora apiculata, Bruguiera gymnorrhiza. Bibit ini didapat dari Tahura (Taman Hutan Raya). Bibit ditanam pada polibag yang telah diisi dengan media tanam yang terdiri atas tanah yang telah dicampur dengan pupuk kandang sapi yang perbandingannya 2:1.Pengamatan dan pengukuran dilakukan setiap minggu sampai umur bibit 3 bulan. Pengukuran dilakukan dengan mengukur tinggi tanaman, diameter batang, jumlah daun, suhu dan kelembaban

\section{Analisis data}

Data yang diperoleh dalam penelitian dianalisis secara kuantitatif dengan menggunakan analysis of varians (Anova). Apabila data yang diperoleh menunjukan perbedaan secara nyata, maka dilanjutkan dengan Duncan Multiple Range Test (DMRT) pada tingkat 5\%. Analisis statistik dengan bantuan software (CoStat Co.). Dalam menentukan jumlah perlakuan dan ulangan dari setiap desain penelitian berpatokan pada ketentuan (p-1)x(r-1) $\geq 15$ (Gomez and Gomez, 2007).

\section{HASIL}

Tabel 1. Rata-rata tinggi batang dari ke-4 jenis mangrove yaitu B.gymnorrhiza, $R$ apiculata, $R$. mucronata, dan $R$. stylosa selama 6-13 MST

\begin{tabular}{lcccccccc}
\hline \multirow{2}{*}{ Nama Jenis Mangrove } & \multicolumn{8}{c}{ Rata rata tinggi batang pada minggu 6-13 setelah tanam $(\mathrm{cm})$} \\
\cline { 2 - 9 } & 6 & 7 & 8 & 9 & 10 & 11 & 12 & 13 \\
\hline B. gymnorrhiza & 13 & 15 & 17 & 19 & 20 & 21 & 22 & 23 \\
R.apiculata & 5.2 & 6.1 & 7 & 8 & 8.7 & 9 & 10 & 10 \\
R. mucronata & 5.6 & 7.3 & 8.3 & 9.2 & 11 & 14 & 15 & 16 \\
R.stylosa & 5.4 & 6.2 & 7.4 & 8.7 & 9.7 & 10 & 11 & 11 \\
\hline
\end{tabular}

Tabel 2. Rata-rata jumlah daun dari ke-4 jenis mangrove yaitu B. gymnorrhiza, $R$. apiculata. $R$. mucronata, dan $R$. stylosa selama 613 MST

\begin{tabular}{lcccccccc}
\hline \multirow{2}{*}{ Nama jenis mangrove } & \multicolumn{8}{c}{ Rata rata jumlah daun pada minggu 6-13 setelah tanam $(\mathrm{cm})$} \\
\cline { 2 - 9 } & 6 & 7 & 8 & 9 & 10 & 11 & 12 & 13 \\
\hline B. gymnorrhiza & 5.7 & 6.3 & 7.8 & 8.8 & 10 & 12 & 13 & 14 \\
R.apiculata & 2.3 & 2.5 & 3.7 & 4 & 4.8 & 5 & 6 & 6 \\
R. mucronata & 2.5 & 3 & 4 & 4.5 & 5 & 6 & 6.67 & 7 \\
R.stylosa & 2.3 & 3 & 3.8 & 4.5 & 5 & 5.67 & 6.5 & 6.83 \\
\hline
\end{tabular}

Tabel 3. Rata-rata diameter batang dari ke-4 jenis mangrove yaitu B. gymnorrhiza, R.apiculata R. mucronata, dan R.stylosa selama 613 MST

\begin{tabular}{lcccccccc}
\hline \multirow{2}{*}{ Nama jenis mangrove } & \multicolumn{8}{c}{ Rata rata diameter batang pada minggu 6-13 setelah tanam $(\mathrm{cm})$} \\
\cline { 2 - 10 } & 6 & 7 & 8 & 9 & 10 & 11 & 12 & 13 \\
\hline B. gymnorrhiza & 0.8 & 0.9 & 1.1 & 1.3 & 1.4 & 1 & 2 & 2 \\
R.apiculata & 0.9 & 0.9 & 1.1 & 1.3 & 1.4 & 2 & 2 & 2 \\
R. mucronata & 0.9 & 0.9 & 1 & 1.2 & 1.33 & 1.47 & 1.53 & 1.6 \\
R.stylosa & 0.8 & 0.9 & 1 & 1.2 & 1.3 & 1.42 & 1.48 & 1.57 \\
\hline
\end{tabular}

Hasil rata-rata penambahan tinggi batang, jumlah daun dan diameter batang per minggu dari ke-4 semai mangrove ada perbedaan dan tidak berbeda. Rata-rata penambahan tinggi batang per minggu yang paling tinggi yaitu dari jenis $R$. mucronata kemudian diikuti berturut turut yaitu B. gymnorrhiza, R.stylosa dan $R$. apiculata dengan nilai rata-rata masing-masing sebesar 1,5, 1,4, 0,8 dan 0,7 (Tabel 1).

Hasil rata-rata penambahan jumlah daun dari ke-4 jenis semai mangrove per minggu mulai minggu 6 sampai minggu ke
13 yang paling tinggi adalah jenis B. gymnorrhiza dan diikuti ketiga jenis lainnya yaitu R.mucronata, $R$. apiculata dan $R$.stylosa dengan nilai masing-masing sebesar 1,2, 0,6, 0,6 dan 0,6 (Tabel 2).

Hasil rata-rata penambahan diameter batang per minggu dihitung mulai minggu ke-6 sampai minggu ke-13 pada ke empat jenis semai mangrove tidak ada perbedaan yaitu sebesar 0,1 (Tabel 3).

Tabel 4. Rata-rata pertumbuhan tinggi batang dari 4 jenis semai mangrove per minggu mulai 6-13 MST

\begin{tabular}{lcccccccc}
\hline \multirow{2}{*}{ Nama Mangrove } & \multicolumn{9}{c}{ pertumbuhann tinggi batang per minggu mulai dari 6-13MST } & \multirow{2}{*}{$\begin{array}{c}\text { Rata- } \\
\text { rata }\end{array}$} \\
\cline { 2 - 8 } & $6-7$ & $7-8$ & $8-9$ & $9-10$ & $10-11$ & $11-12$ & $12-13$ & \\
\hline B. gymnorrhiza & 2 & 1.5 & 1.9 & 1.5 & 0.8 & 0.8 & 1.1 & 1.4 \\
R.mucronata & 1.6 & 1.1 & 0.9 & 1.7 & 2.7 & 1.4 & 1 & 1.5 \\
R. apiculata & 0.9 & 0.9 & 1 & 0.7 & 0.6 & 0.4 & 0.5 & 0.7 \\
R.stylosa & 0.8 & 1.2 & 1.4 & 1 & 0.6 & 0.3 & 0.5 & 0.8 \\
\hline
\end{tabular}

Tabel 5. Rata-rata pertumbuhan jumlah daun dari 4 jenis semai mangrove per minggu mulai 6-13 MST 


\begin{tabular}{lcccccccc}
\hline \multirow{2}{*}{ Nama Mangrove } & \multicolumn{9}{c}{ Pertumbuhan jumlah daun per minggu mulai dari 6-13MST } & \multirow{2}{*}{$\begin{array}{c}\text { Rata- } \\
\text { rata }\end{array}$} \\
\cline { 2 - 7 } & $6-7$ & $7-8$ & $8-9$ & $9-10$ & $10-11$ & $11-12$ & $12-13$ & \\
\hline B. gymnorrhiza & 0.7 & 1.5 & 1 & 1.3 & 1.3 & 1.8 & 0.5 & 1.2 \\
R. mucronata & 0.5 & 1 & 0.5 & 0.5 & 1 & 0.7 & 0.3 & 0.6 \\
R. apiculata & 0.2 & 1.2 & 0.3 & 0.8 & 0.5 & 0.7 & 0.3 & 0.6 \\
R.stylosa & 0.7 & 0.8 & 0.7 & 0.5 & 0.7 & 0.8 & 0.3 & 0.6 \\
\hline
\end{tabular}

Tabel 6. Rata-rata pertumbuhan diameter batang dari 4 jenis semai mangrove per minggu mulai 6-13 MST

\begin{tabular}{lcccccccc}
\hline \multirow{2}{*}{ Nama Mangrove } & \multicolumn{9}{c}{ Pertumbuhan diameter batang per minggu mulai dari 6-13MST } & \multirow{2}{*}{$\begin{array}{c}\text { Rata- } \\
\text { rata }\end{array}$} \\
\cline { 2 - 9 } & $6-7$ & $7-8$ & $8-9$ & $9-10$ & $10-11$ & $11-12$ & $12-13$ & \\
\hline B. gymnorrhiza & 0.1 & 0.1 & 0.2 & 0.1 & 0.1 & 0.1 & 0.1 & 0.1 \\
R. mucronata & 0 & 0.1 & 0.2 & 0.1 & 0.1 & 0.1 & 0.1 & 0.1 \\
R. apiculata & 0.1 & 0.1 & 0.2 & 0.1 & 0.1 & 0.1 & 0.03 & 0.1 \\
R. stylosa & 0.1 & 0.1 & 0.2 & 0.2 & 0.1 & 0.1 & 0.1 & 0.1 \\
\hline
\end{tabular}

Perkembangan pertumbuhan tinggi batang semai mangrove $B$. gymnorrhiza yang diukur mulai minggu ke-6 awalnya mengalami penurunan dari $2 \mathrm{~cm}$ menjadi 1,5 kemudian terjadi kenaikan lagi menjadi $1,9 \mathrm{~cm}$ yang menjadi titik pertumbuhan optimal yang akhirnya penambahan tinggi hanya $1,1 \mathrm{~cm}$ pada minggu 13 . Jenis $R$. mucronata memiliki titik optimal penambahan tinggi batang pada minggu 11. Sedangkan jenis $R$. apiculata dan $R$. stylosa memiliki titik optimal pertumbuhan pada minggu ke 9 (Tabel 4, Gambar 1 ).

Perkembangan pertumbuhan jumlah daun semai mangrove $B$. gymnorrhiza yang diukur mulai minggu ke-6 awalnya mengalami kenaikan dari $0,7 \mathrm{~cm}$ menjadi $1,5 \mathrm{~cm}$ kemudian turun menjadi $1 \mathrm{~cm}$ selanjutnya titik pertumbuhan optimal $1,8 \mathrm{~cm}$ pada minggu 12 yang akhirnya penambahan tinggi hanya $0,5 \mathrm{~cm}$ pada minggu 13 . Jenis $R$. mucronata memiliki titik optimal penambahan jumlah daun pada minggu ke-8 dan 11. Jenis $R$. apiculata titik optimal penambahan jumlah daun pada minggu ke-8 dan $R$. stylosa memiliki titik optimal pertumbuhan pada minggu ke 8 dan 12 (Tabel 5, Gambar 2).

Perkembangan pertumbuhan diameter batang semai mangrove B. gymnorrhiza, $R$. mucronata, $R$. apiculata dan $R$. stylosa mencapai titik optimal pada minggu ke-8 (Tabel 6 , Gambar 3).

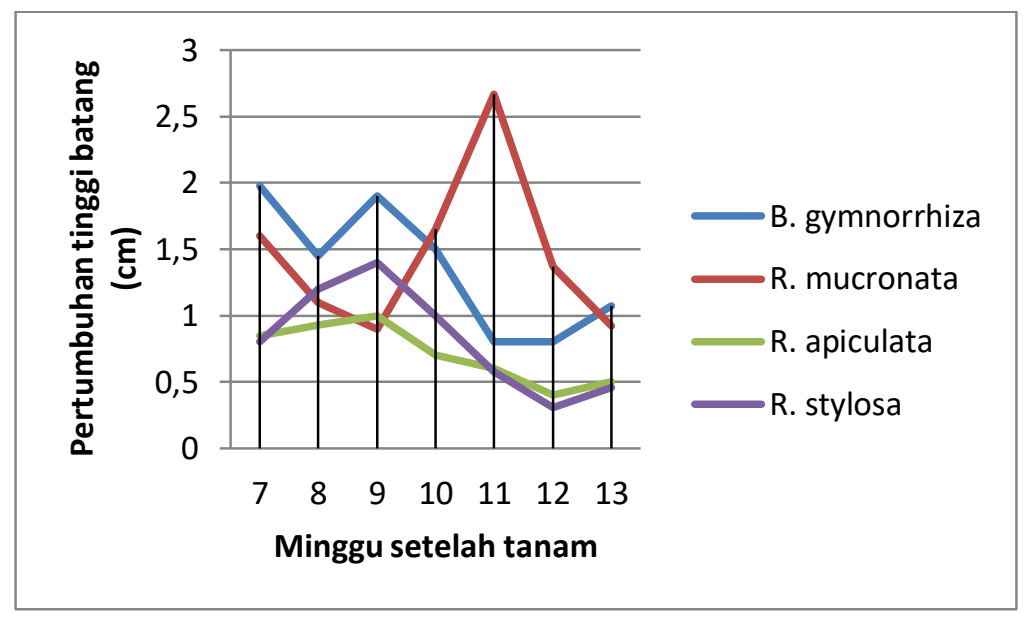

Gambar 1. Perkembangan pertumbuhan tinggi batang dari 4 semai mangrove per minggu mulai 6-13 MST

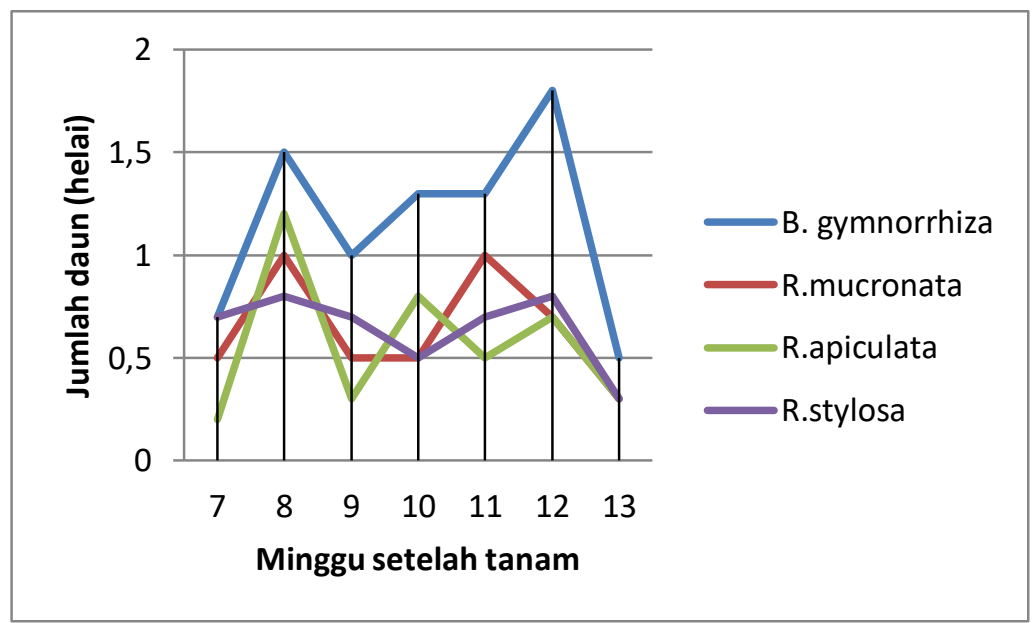

Gambar 2. Perkembangan pertumbuhan jumlah daun dari 4 semai mangrove per minggu mulai 6-13 MST 


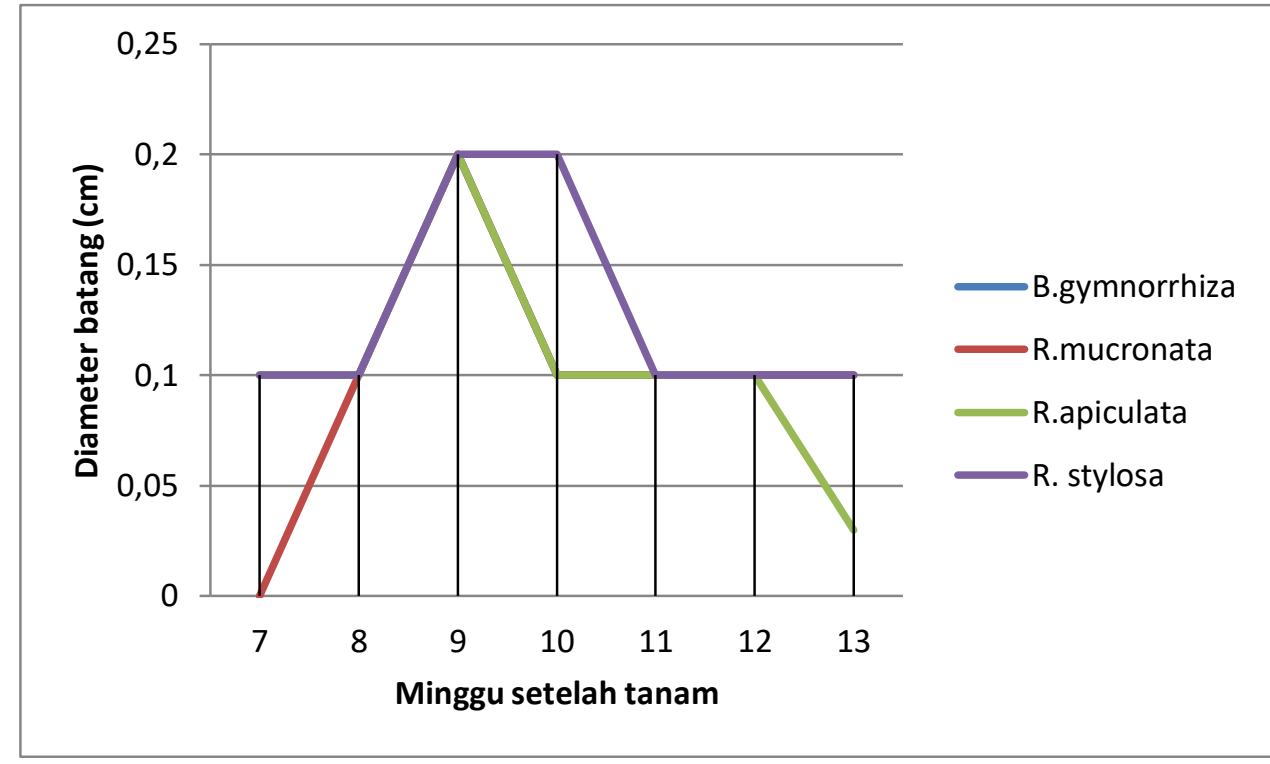

Gambar 3. Perkembangan pertumbuhan diameter batang dari 4 semai mangrove per minggu mulai 6-13 MST

Hasil analisis statistik dari empat jenis bibit mangrove yaitu B. gymnorrhiza, R.mucronata, $R$. stylosa dan $R$. apiculata pada pertumbuhan tinggi batang, jumlah daun dan diameter batang pada 13 MST

\begin{tabular}{lclrlr}
\hline \multicolumn{1}{c}{$\begin{array}{c}\text { Jenis } \\
\text { mangrove }\end{array}$} & $\begin{array}{c}\text { Tinggi } \\
\text { batang } \\
(\mathrm{cm})\end{array}$ & $\begin{array}{c}\text { Jenis } \\
\text { mangrove }\end{array}$ & $\begin{array}{c}\text { Jumla } \\
\mathrm{h} \\
\mathrm{daun} \\
(\mathrm{bh})\end{array}$ & $\begin{array}{c}\text { Jenis } \\
\text { mangrove }\end{array}$ & $\begin{array}{c}\text { Diamet } \\
\text { er } \\
\text { batang } \\
(\mathrm{cm})\end{array}$ \\
\hline B. & $20,5 \mathrm{a}^{*}$ & B.. & $13,8 \mathrm{a}$ & B. gymnorrhiza & $1,67 \mathrm{a}^{*}$ \\
gymnorrhiza & & gymnorrhiza & $*$ & & \\
R. mucronata & $15,8 \mathrm{~b}$ & R. stylosa & $8,3 \mathrm{~b}$ & R. apiculata & $1,65 \mathrm{ab}$ \\
R. stylosa & $11,1 \mathrm{c}$ & R. mucronata & $7,2 \mathrm{~b}$ & R. mucronata & $1,6 \mathrm{ab}$ \\
R. apiculata & $10,1 \mathrm{c}$ & R. apiculata & $6,3 \mathrm{~b}$ & R. stylosa & $1,57 \mathrm{~b}$ \\
\hline
\end{tabular}

* Angka yang diikuti oleh huruf yang sama menunjukkan berbeda tidak nyata berdasarkan Duncan's Multiple Range Test pada taraf $5 \%$

\section{PEMBAHASAN}

Dari hasil pengamatan dan analisis data yang diperoleh pada keempat jenis bibit tanaman mangrove yaitu $B$. gymnorrhiza, R.apiculata, R. mucronata, dan R. stylosa dan 3 variabel seperti tinggi batang, jumlah daun dan diameter batang, bibit jenis $R$. mucronata dan B. gymnorrhiza memiliki rata-rata pertumbuhan tinggi batang lebih cepat dibandingkan lainnya. Jenis $R$. mucronata memiliki pertumbuhan tinggi batang yang baik karena pada waktu penanaman bibit menggunakan propagul dengan melepas keping buah (Rusdiana, et al., 2015). Jenis mangrove tersebut akan tumbuh optimal pada suplai air tawar yang cukup. Misalnya dekat dengan daerah muara sungai. Tanaman B.gymnorrhiza juga memiliki pertumbuhan tinggi batang yang baik karena tanaman ini sangat cocok dengan air yang memiliki kandungan salinitas. Menurut (Soegiyanto, 1987; Chapman, 1966; Yusniawati et al., 2017) bahwa tanaman B. gymnorrhiza dapat tumbuh dengan baik jika mendapatkan suplai air tawar dengan salinitas kurang dari 3\%. Dengan salinitas yang rendah dapat meningkatkan pertumbuhan tinggi tanaman B. gymnorrhiza. Faktor internal berpengaruh terhadap pertumbuhan tanaman. Disamping itu, faktor lingkungan seperti tanah berlumpur memacu pertumbuhan daun, jika nutrisi media cukup bagi pertumbuhan. Intensitas cahaya yang diterima berpengaruh juga terhadap pertumbuhan tanaman. Tanaman mangrove hanya memanfaatkan $50 \%$ dari cahaya matahari (Chapman, 1966).

Dari hasil pengamatan yang dilakukan setiap minggu, dapat dilihat pertambahan tinggi tanaman pada setiap jenis tanaman. Pertambahan tinggi tersebut berkisar antara 0,7 sampai $1,4 \mathrm{~cm}$. Pertambahan tinggi tanaman yang tidak begitu cepat disebabkan karena tanaman tersebut merupakan jenis tanaman tahunan. Ada beberapa tanaman yang pertumbuhan tinggi tanamannya sangat cepat karena akar tanaman tersebut sudah menembus polibag sehingga tanaman mendapatkan nutrisi tambahan dari tanah yang ada di sekitarnya. Menurut Rusdiana et al., (2015) penanaman semai mangrove tanpa polibag menghasilkan tinggi tanaman lebih tinggi jika dibandingkan dengan menggunakan polibag. Penanaman tanpa polibag ratarata pertumbuhan $3.38 \mathrm{~cm}$, mencapai $32.22 \%$ dari tinggi awal semai, sedangkan penanaman dengan polibag pertumbuhannya $1.24 \mathrm{~cm}$, mencapai $11.79 \%$ dari tinggi awal semai.

Jenis B.gymnorrhiza memiliki rata-rata pertumbuhan jumlah daun yang lebih banyak dibandingkan dengan ketiga semai lainnya. Salah satu penyebabnya adalah bahwa semai $B$. gymnorrhiza sangat bagus dan cocok tumbuh dengan penyiraman secukupnya. Menurut Permatasari dan Kusmana, 2011 bahwa salah satu faktor yang mempengaruhi pertumbuhan semai mangrove adalah perlakuan penyiraman. Penyiraman tanpa genangan memiliki potensi yang lebih baik terhadap pertumbuhan semai mangrove. Kualitas air atau kekeruhan dan $\mathrm{pH}$ berpengaruh terhadap pertumbuhan tinggi tanaman, jumlah daun dan diameter batang semai mangrove (Andarani et al., 2016)

Jumlah daun tanaman pada jenis $B$. gymnorrhiza sudah mencapai jumlah 14 helai, sehingga bibit tersebut sudah siap ditanam ke lapangan. Pada fase bibit, daun tidak dimanfaatkan secara optimal untuk proses asimilasi. Tetapi lebih banyak digunakan untuk mengontrol kalenjar garam (Chapman, 1966).

Terkait dengan tipe benih, keempat jenis tanaman mangrove yaitu tipe benih vivipari. Hal tersebut menguntungkan tanaman agar dapat hidup pada daerah pasang - surut. Jadi tipe 
benih merupakan salah satu faktor adaptasi tanaman tersebut terhadap lingkungan (Chapman, 1966).

Secara morfologi bentuk benih vivipari, memungkinkan tanaman untuk berkecambah di daerah pasang surut (Chapman, 1966). Dilihat dari kondisi daun pada saat pengamatan, masingmasing jenis tanaman Rhizophora mucronata, Rhizophora stylosa, Rhizophora apiculata, dan Bruguiera gymnorrhiza banyak berlubang daunnya. Hal tersebut disebabkan oleh serangan hama serangga Balisepta. Hama tersebut menyerang pada saat sebelum pucuk membuka dimana serangga sudah masuk ke dalam pucuk dan memakan daun sehingga daun berlubang (Hochindre et al., 2004). Hama lainnya adalah kepiting. Kepiting terbawa pada saat air pasang. Jenis kepiting tersebut rnemakan daun-daun muda bibit tanaman mangrove pada malam hari.

Semai benih dilakukan bulan Desember, berarti seleksi bibit yang ada sudah siap ditanam. Jenis Rhizophora mucronata sudah siap tanam saat umur (4-5 bulanan). Jumlah daun sudah memenuhi persyaratan yaitu 7 helai dan tinggi bibit mencapai $55 \mathrm{~cm}$ juga telah memenuhi persyaratan untuk siap tanam (Hochindre et.al., 2004). Jenis bibit mangrove yang pertumbuhannya baik maka bibit tanaman mangrove sudah siap sebagai bibit siap tanam.

Pertumbuhan bibit tanaman mangrove dapat terhenti jika pucuk tidak dapat membuka. Ciri-ciri awal adalah daun layu, akhirnya tanaman menjadi kering kemudian mati. Hal tersebut karena daun tidak dapat melakukan fotosintesa dan menghasilkan energi sehingga berpengaruh pada pertumbuhan tanaman.

\section{SIMPULAN}

Rata-rata pertumbuhan tinggi batang dari ke-4 semai mangrove yaitu R.mucronata, B. gymnorrhiza, $R$. stylosa dan $R$. apiculata yang diukur dari $6-13$ MST berturut-turut yaitu $1,5 \mathrm{~cm}, 1,4 \mathrm{~cm}, 0,8 \mathrm{~cm}$ dan $0,7 \mathrm{~cm}$. Rata rata jumlah daun dari ke4 semai mangrove berturut-turut yaitu $0,6,1,2,0,6$, dan 0,6 helai dan rata-rata diameter batang ke-4 semai mangrove adalah 0,1 $\mathrm{cm}$. Tanaman semai mangrove jenis R.mucronata dan B.gymnorrhiza yang menghasilkan rata-rata pertumbuhan tinggi batang yang lebih tinggi dibandingkan lainnya, dan jenis B. gymnorrhiza yang menghasilkan rata-rata jumlah daun yang paling tinggi dibandingkan ketiga jenis lainnya.

\section{KEPUSTAKAAN}

Andarani,T., Hastuti,E.D., Rini Budihastuti, R. 2016. Perubahan Kualitas Air dan Hubungannya dengan Pertumbuhan Semai Rhizophora mucronata Lamk. Berdasarkan Waktu Pengamatan yang Berbeda pada Saluran Tambak Wanamina. Jurnal Biologi, 5(1):72-81.

Darmadi, A.A.Kt. 2017. Etnobotani. Ragam etnobotani di Bali, Udayana University Press.

Departemen kehutanan, 1995, Rancangan Percobaan (Experimental Design) Studi Penanaman Mangrove Di Delta Area Berlumpur., Kantor Wilayah Propinsi Bali, Balai Rehabilitasi Lahan Dan Konservasi Tanah VII.

Departemen Kehutanan dan Proyek Pengembangan Hutan Bakau Bali, 1995, Manfaat Hutan Mangrove Bagi Kehidupan dan Kelestarian Alam.

Departemen Kehutanan, Kantor Wilayah Provinsi Bali, 1996, Pengembangan Hutan Mangrove di propinsi Bali. Balai Rehabilitasi Lahan Dan Konservasi Tanah VII.
Departemen Kehutanan dan Proyek Pengembangan Hutan bakau Bali,1997, Teknik Penyiapan Bibit Bakau Jenis Rhizophora (Rhizophora Spesies).

Chapman, V. J. 1966. Mangrove Vegetation. Inder A. R. Gantner Verlag Kommanditjesellschaft.

Gomes, K.A., Gomes, A.A. 2007. Prosedur Statistik untuk Penelitian Pertanian. Edisi Kedua. Penerbit Univeristas Indonesia (UI-Press).

Hochindre H., O Suko, A Ida. 2004 Manual Persemaian Mangrove Di Bali. Departemen Kehutanan dan Perkebunan Republik Indonesia dan Japan Internasional Cooperation Agency.

Kenichi, O., S. Takasi, M. Shinichi, N. Hiromitsu I. Shigeru, S. Hiroshi, H Hiroyuki. 1999. Short Item Expert Reports. The Development OfSustainable Mangrove Management Project.

Khazali,M. 1999. Panduan TeknisPenanaman Mangrove Bersama Masyarakat. Ditjen. Rehabilitasi Lahan Perhutanan Sosial dan Canada Fund. Bogor

Kitamura, S. 1997. Handbook of Mangroves in Indonesia. Bali and Lombok. ISME and JICA. Bali.

Kurniaty, R dan Danu. 2012. Teknik persemaian. Balai Penelitian Teknologi Perbenihan Tanaman Hutan. Bogor

Mughofara,A. Masykurib,M., Setyono,P. 2018. Zonasi Dan Komposisi Vegetasi Hutan Mangrove Pantai Cengkrong Desa Karanggandu Kabupaten Trenggalek Provinsi Jawa Timur. Jurnal Pengelolaan Sumberdaya Alam dan Lingkungan, 8(1): 77-85

Indah Permatasari, I. dan Cecep Kusmana, C. 2011. Respon Pertumbuhan Semai Tancang (Bruguiera gymnorrhiza (L.) Lamk.) Terhadap Tingkat Penggenangan di Kawasan Mangrove Jalan Tol Sedyatmo, Jakarta Utara. JURNAL SILVIKULTUR TROPIKA,2(3):181 - 186.

Rusdiana, O., Sukendro, A., dan Baiquni, R.A. 2015. Pertumbuhan Bakau Merah (Rhizophora Mucronata) di Persemaian Mangrove Desa Muara, Kecamatan Teluk Naga, Kabupaten Tangerang. Jurnal Silvikultur Tropika, 6(3):172-178.

Soegiyantto, Drs. 1983. Kenalilah Flora Pantai Kita. Jakarta : Wijaya.

Suryadipura, 2004. Materi Kuliah Ekosistem Estuaria dan Ekosistem Mangrove. Laboratorium Ekologi Jurusan Biologi Fakultas Matematika dan Ilmu Ilmu Pengetahuan Alam Universitas Udayana. Denpasar.

Tanuguchi, K., S. Takashima, O. Suka, 2004 Manual Silvikultur Mangrove Untuk Bali Lombok. Departemen Kehutanan dan Perkebunan Republik Indonesia dan Japan International Cooperation Agency.

Yusniawati, Mukarlina, Wardoyo, E.R.P. 2017. Pertumbuhan Semai Bakau Putih (Bruguiera cylindrica (L.) BI.) pada Tingkat Salinitas yang Berbeda. Protobiont, 6(3):31-36. 